\title{
MR imaging in Kallmann syndrome: a case report
}

Sameera Allu', Rajani Gorantla ${ }^{2^{*}}$ (D) and D. Ankamma Rao²

\begin{abstract}
Background: A rare genetic disorder called Kallmann syndrome results from a defect in the neuronal migration of olfactory axons and gonadotropin-releasing hormone neurons. MR imaging helps in confirming the diagnosis of Kallmann syndrome with characteristic morphological findings in the brain, in clinically suspicious cases of hypogonadotropic hypogonadism with anosmia/hyposmia.

Case presentation: A 15-year-old male teenager presented with complaints of a small penis and anosmia. Hormonal assay of gonadotropins and testosterone revealed low serum concentrations. MRI brain revealed the absence of the olfactory bulbs in the olfactory grooves and hypoplastic olfactory sulcus. With the gonadotropic hormonal assay showing low levels and characteristic MR imaging features of absent olfactory tracts and olfactory sulcus, the diagnosis of Kallmann syndrome was confirmed.

Conclusions: Morphological abnormalities of olfactory tracts and olfactory sulcus can be accurately depicted with MR imaging through anterior fossa in the coronal plane. Therefore, MR imaging of the brain plays a significant role in diagnosing uncommon Kallmann syndrome and other associated brain abnormalities.
\end{abstract}

Keywords: Kallmann syndrome, MR imaging, Hypogonadism, Olfactory, Case report

\section{Background}

Kallmann syndrome (KS) is a rare genetic disorder with a defect in neuronal migration of olfactory axons and gonadotropin-releasing hormone neurons. The estimated prevalence is one in 10,000 males and one in 50,000 females [1]. Clinical features include hypogonadotropic hypogonadism and hyposmia or anosmia. KS patients are anosmic since birth, but this is not apparent, and the diagnosis is usually made in the teenage when the child fails to attain puberty. MR imaging of the brain is a useful adjunct in making a diagnosis with characteristic morphological findings of the olfactory tracts and olfactory sulcus. In this report, we present a case of KS with classic imaging features in the MRI brain.

\footnotetext{
* Correspondence: drraaji@gmail.com

${ }^{2}$ NRI Medical College \& Hospital, Mangalagiri, Guntur Dst. 522503, India Full list of author information is available at the end of the article
}

\section{Case presentation}

A 15-year-old male teenager presented to the endocrinology department for evaluation of a small penis. On further elicitation of medical history, he complained of anosmia, and on examination, the penis and testes were small. No other significant past medical and surgical history was noted. Evaluation of hypogonadism with a hormonal assay of FSH, LH, and testosterone, along with $\mathrm{GnRH}$ stimulation test, revealed their serum concentrations to be below the normal limits $(\mathrm{LH}=0.21 \mathrm{U} / \mathrm{L}, \mathrm{FSH}=0.10 \mathrm{U} / \mathrm{L}$, and testosterone $=0.24 \mathrm{ng} / \mathrm{ml}$ and after HCG stimulation, the levels of gonadotropins increased to $\mathrm{LH}=1.16 \mathrm{U} /$ $\mathrm{L}$ and $\mathrm{FSH}=1.35 \mathrm{U} / \mathrm{L}$ ). With this clinical picture and biochemical investigations, further workup was initiated with referral to the radiology department for MRI brain with contrast to look for any intracranial pathology and olfactory tracts in particular, in the view of suspicion of KS. MRI brain in the coronal plane through the anterior cranial fossa region 


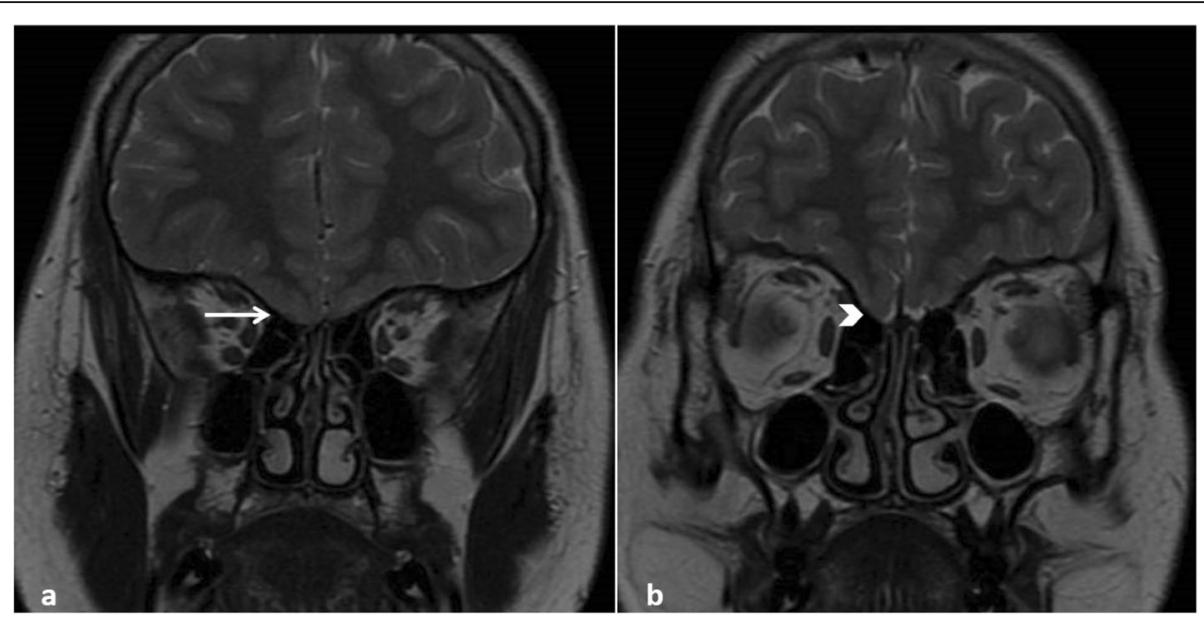

Fig. 1 a, b T2 weighted coronal MRI images of the brain through anterior cranial fossa showing hypoplastic olfactory sulcus (arrow in a) with absence of olfactory bulbs in the olfactory grooves on both sides (arrow head in $\mathbf{b}$ )

revealed the absence of an olfactory bulb in the olfactory groove on both sides, and also, there was hypoplastic olfactory sulcus between the gyrus rectus and medial orbital gyrus (Fig. 1a, b). The rest of the sulci and gyri are normal. Sella is normal in size, measuring $10.8 \times 5.6 \times 8.1 \mathrm{~mm}$. The anterior pituitary gland is normal in size (> $5 \mathrm{~mm}$ height). The posterior pituitary bright spot is noted within the sella. The infundibular stalk is in the midline (Fig. 2a, b). The rest of the brain is unremarkable, with no other abnormalities detected. These imaging features were characteristic of KS. With the relevant clinical picture, biochemical investigations showing low gonadotropic hormonal assays, and MR imaging features of absent olfactory tracts and hypoplastic olfactory sulcus, the diagnosis of KS was confirmed. The patient is treated with exogenous sex steroids for hypogonadism.

\section{Discussion}

KS results from defective neuronal migration of $\mathrm{GnRH}$ secreting neurons from the olfactory placode to the forebrain and hypothalamus, resulting in GnRH deficiency followed by LH and FSH deficiencies [2]. This decrease in the levels of gonadotropins was noted in our case. In a study conducted by Koenigkam-Santos et al. [3], it was found that the most common findings in KS patients were olfactory bulb and sulcus aplasia (85\%). However, their data suggest that there is higher accuracy in predicting KS by evaluating the olfactory bulbs than olfactory sulcus. This is because, with olfactory bulb aplasia in some patients, different degrees of sulcus hypoplasia were demonstrated. Our case study's findings, absence olfactory bulbs with hypoplastic olfactory sulci on both sides, correlate with the study mentioned above's findings. Developmental abnormality of the olfactory

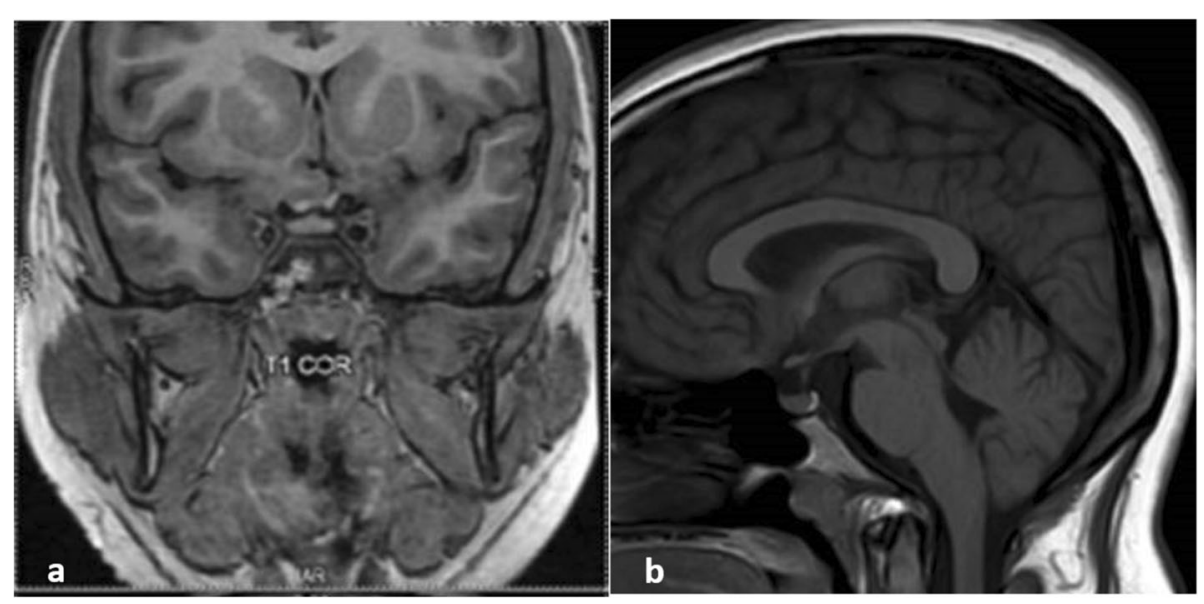

Fig. 2 a, b T1 weighted coronal and sagittal MR images of the brain through sella showing normal-sized sella turcica and anterior pituitary gland. The posterior pituitary bright spot is seen within the sella. The infundibular stalk is in the midline 
placode results in hypoplasia to aplasia of olfactory bulbs and sulci. Other associated anomalies, including various cardiovascular abnormalities, renal agenesis, cryptorchidism, short fourth metacarpal, and facial anomalies, have been reported [4]. These associated anomalies were not seen in our case.

MR imaging of the brain plays a vital role in the diagnosis of KS. Suzuki et al. [5] were the pioneers in describing the visualization of olfactory bulbs and tracts on MRI scans. The works by Yousem et al. [6] demonstrated that MRI could assess accurate volumetric measurements of the olfactory bulbs in various pathological conditions. This contribution had a high impact clinically because the olfactory bulb size and function closely correlate [7].

Optimal visualization of olfactory bulbs and tracts is with MR imaging through anterior fossa in the coronal plane. The sequences preferred for the olfactory system's structural evaluation include high-resolution coronal fast spin-echo T2W and T1W images [8]. The normal anatomy of the region consists of olfactory bulbs located in the olfactory grooves, which run along with the cribriform plate and the olfactory sulcus in the inferior surface of the frontal lobes, separating the gyrus rectus from the medial orbital gyrus. These are the structures abnormal in KS. In our case, there was an absence of the olfactory bulb in the olfactory groove, and there was hypoplastic olfactory sulcus between the gyrus rectus and medial orbital gyrus on both sides. For perfect visualization of the olfactory bulbs, it is recommended that scanning in the coronal plane with large matrix size and decreased intersection gap is needed, demonstrating anatomical olfactory tract overview, detecting parenchymal lesions, and olfactory bulb volumetry $[9,8]$. In some cases, there may be hypoplasia of anterior pituitary probably secondary to limited stimulation due to the absence of hypothalamic GnRH neurons. However, the anterior pituitary was normal in the present case.

In a study by Manara et al. [10], MR imaging was done on an outsized group of male KS patients using conventional and advanced sequences, including 3D-T1, FLAIR, and diffusion tensor imaging. Voxel-based morphometry, sulcation, curvature, and cortical thickness analyses and tract-based spatial statistics were performed, which showed significant brain changes specifically involving the gyri recti and the contiguous medial orbital-frontal regions. Even though further validation is warranted, this study has portrayed significant morphologic and structural brain changes that were likely driven by olfactory bulb hypo-/aplasia, selectively involving the basal forebrain cortex, which seemed to be is far more consistent than simple hypoplasia of the olfactory sulcus. These changes could not be assessed in the present case as the advanced techniques were not employed in the imaging.
Genetic testing is also employed in further evaluation of KS to detect the mutations in the respective genes. However, genetic testing was not done in the present case due to limited facilities. In this case, treatment is supportive, with exogenous sex steroids to restore normal pubertal development and, in some cases, normal fertility [11]

\section{Conclusions}

The diagnosis of Kallmann syndrome in an adult is made with clinical features of hypogonadism and hyposmia/anosmia with co-existing decreased serum levels of gonadotropic hormones and sex steroids, and characteristic imaging features. MRI plays a meaningful role in establishing the KS diagnosis by demonstrating characteristic morphologic abnormalities in olfactory sulci and tracts and other associated brain changes.

\section{Abbreviations}

MR: Magnetic resonance; MRI: Magnetic resonance imaging;

$\mathrm{GnRH}$ : Gonadotropic-releasing hormone; KS: Kallmann syndrome; FSH: Follicular-stimulating hormone; LH: Luteinizing hormone; HCG: Human chorionic gonadotropin

\section{Acknowledgements \\ Not applicable.}

\section{Authors' contributions}

RG is the author who gathered the data and submitted it to the journal. SA wrote the manuscript and edited the data. ARD has helped in the interpretation of the data and guiding the work. All authors have read and approved the final manuscript. All authors have agreed both to be personally accountable for their own contributions and to ensure that questions related to the accuracy or integrity of any part of the work, even ones in which the author was not personally involved, are appropriately investigated, resolved, and the resolution documented in the literature.

\section{Funding}

Not applicable.

Availability of data and materials

The datasets used and/or analyzed during the current study are available from the corresponding author on reasonable request.

\section{Ethics approval and consent to participate}

This case report was approved by the ethical committee of NRI academy of health sciences. The patient included in this study gave verbal informed consent to participate in this study.

\section{Consent for publication}

Written informed consent was obtained from the parent of the patient for publication of this case report and accompanying images.

\section{Competing interests}

The authors declare that they have no financial or non-financial competing interests.

\section{Author details}

${ }^{1}$ King George Hospital, Visakhapatnam, India. ${ }^{2}$ NRI Medical College \& Hospital, Mangalagiri, Guntur Dst. 522503, India. 
Received: 25 June 2020 Accepted: 30 August 2020

Published online: 11 September 2020

References

1. Vogl TJ, Stemmler J, Heye B et-al. (1994) Kallmann syndrome versus idiopathic hypogonadotropic hypogonadism at MR imaging. Radiology.191 (1): 53-57. https://doi.org/https://doi.org/10.1148/radiology.191.1.8134597

2. Doraiswamy M, Potts JM, Axelson DA, et al. (1992) MR assessment of pituitary gland morphology in healthy volunteers: age and gender-related differences. Am J Neuroradiol. 13:1295-1299. PubMed ID: 1414818

3. Koenigkam-Santos M, Santos AC, Versiani BR, Diniz PR, Junior JE, De Castro M. (2011) Quantitative magnetic resonance imaging evaluation of the olfactory system in Kallmann syndrome: correlation with a clinical smell test. Neuroendocrinology. 94:209-217. https://doi.org/https://doi.org/10.1159/ 000328437

4. Moorman JR, Crain B, Osborne D. (1984) Kallmann syndrome with associated cardiovascular and intracranial abnormalities. Am J Med 77:369372. https://doi.org/https://doi.org/10.1016/0002-9343(84)90724-1

5. Suzuki M, Takashima T, Kadoya M, Takahashi S, Miyayama S, Taira S (1989) MR imaging of olfactory bulbs and tracts. Am J Neuroradiol 10:955-957 http://www.ajnr.org/content/10/5/955

6. Yousem DM, Turner WJ, Li C, Snyder PJ, Doty RL (1993) Kallmann syndrome: MR evaluation of olfactory system. AJNR Am J Neuroradiol 14:839-843 http://www.ajnr.org/content/14/4/839

7. Duprez TP, Rombaux P. (2010) Imaging the olfactory tract. Eur J Radiol 74: 288-298. https://doi.org/https://doi.org/10.1016/j.ejrad.2009.05.065

8. Freitas P, Carvalho S, Ribeiro F, Marnoto D, Martins F. (2001) Neuroradiology of Kallmann syndrome. Acta Medica Port. 14:123-126. PubMed ID: 11321967

9. Knorr JR, Ragland RL, Brown RS, Gelber N (1993) Kallmann syndrome: MR findings. AJNR Am J Neuroradiol 14:845-851 http://www.ajnr.org/ content/14/4/845

10. Manara R, Salvalaggio A, Favaro A, Palumbo V, Citton V, Elefante A, Brunetti A, Di Salle F, Bonanni G, A.A. Sinisi and for the Kallmann Syndrome Neuroradiological Study Group (2014) Brain changes in Kallmann syndrome. Am J Neuroradiol 35(9):1700-1706 http://www.ajnr.org/content/35/9/1700

11. Madhu SV, Kant S, Holla W, Arora R, Rathi S (2012) Unusual presentation of Kallmann syndrome with contiguous gene deletion in three siblings of a family. Indian J Endocrinol Metab 16:326-328 http://www.ijem.in/article. asp?issn $=2230-8210$; year $=2012$; volume $=16$; issue $=8 ;$ spage $=326$; epage $=328$; aulast $=$ Madhu; $t=5$

\section{Publisher's Note}

Springer Nature remains neutral with regard to jurisdictional claims in published maps and institutional affiliations.

\section{Submit your manuscript to a SpringerOpen ${ }^{\circ}$ journal and benefit from:}

- Convenient online submission

- Rigorous peer review

- Open access: articles freely available online

- High visibility within the field

- Retaining the copyright to your article

Submit your next manuscript at $\boldsymbol{\nabla}$ springeropen.com 